\title{
An investigation of blended learning to support reading instruction in elementary schools
}

\author{
Paul Macaruso $^{1} \cdot$ Shani Wilkes $^{2,3} \cdot$ Jen Elise Prescott ${ }^{2,4}$ \\ Published online: 21 June 2020 \\ (C) The Author(s) 2020
}

\begin{abstract}
Research is needed to address the possible benefits of blended learning as a form of reading instruction in elementary schools. Blended learning combines teacher-led instruction with digital technology. We had an opportunity to evaluate the effects of blended learning for students in kindergarten through fifth grade within a charter school network. Administrators in three schools chose to adopt a blended learning program during the 2016-2017 school year. There were 2217 students in the treatment schools. Treatment students were compared to 1504 students in three control schools where the standard form of instruction was maintained. Prior to implementation of blended learning, treatment students performed significantly below control students on a standardized reading test. At the end of the school year, treatment students showed greater gains on the reading test than control students and group differences disappeared. Further analyses revealed that reading gains were uniform across grades and ethnic categories. These outcomes point to the viability of using blended learning for reading instruction in elementary schools.
\end{abstract}

Keywords Blended learning $\cdot$ Literacy $\cdot$ Elementary school $\cdot$ Reading proficiency

\section{Introduction}

When students fail to read proficiently as they reach the end of elementary school, they often face persistent struggles through the rest of their academic career, and such students have particularly high attrition rates in high school (Fiester 2013). According to a recent U.S. government report, only $37 \%$ of fourth graders scored at or above a proficiency level on the National Assessment for Educational Proficiency (National Center for Education Statistics 2017). Reading outcomes for U.S. students from low socioeconomic status (SES)

Shani Wilkes

research@lexialearning.com

1 Community College of Rhode Island, Warwick, USA

2 Lexia ${ }^{\circ}$ Learning, a Rosetta Stone ${ }^{\circ}$ Company, 300 Baker Ave, Suite 320, Concord, MA 01742, USA

3 Present Address: Combined Jewish Philanthropies, Boston, MA, USA

4 Present Address: Massachusetts Bay Transit Authority, Boston, MA, USA 
backgrounds are even more disturbing. Just $22 \%$ of these students scored at or above a proficiency level in fourth grade (National Center for Education Statistics 2017). Given the present situation, educators need to identify and promote the most effective forms of reading instruction in elementary schools, especially for students from low SES backgrounds.

\section{Literature review}

\section{Digital technology}

One possible way of enhancing reading instruction in elementary schools is to utilize digital technology to a greater extent. In fact, the use of computers in education dates back at least 40 years (see reviews by Cheung and Slavin 2013; MacArthur et al. 2001). However, whether the use of technology in classrooms is actually beneficial continues to be a topic of debate. In an early review and meta-analysis, Torgerson and Zhu (2004) reported null findings regarding the benefits of information and communications technology (ICT) for reading comprehension. More generally, Cuban (1986) argued that because teachers are not well-versed in effectively using technology to advance learning, students benefit more from traditional instruction. Even today, less than a third of teachers responded that digital technology supports innovation in their classrooms (Herold 2019). In a recent meta-analysis of studies on computer applications in education, Chauhan (2017) reported moderate benefits of technology use in elementary schools, finding that overall, applications showed more promise when offered in informal settings (e.g., at home or in community centers) compared to classroom use.

As a recent example of a technology-based study, Putman (2017) investigated the benefits of a popular digital program iStation (https://www.istation.com/Reading) to build reading skills in kindergarten students. The study compared students who did or did not use iStation in their classrooms and found that students who used iStation showed higher performance than non-users on basic reading skills such as letter-sound knowledge. Within classrooms using iStation, the authors identified a relationship between level of teachers' literacy support and performance on higher level reading skills. It was suggested that perhaps the best form of reading instruction should couple the use of technology with quality teacher-led instruction.

\section{Blended learning}

The integration of teacher-led instruction with digital technology is the hallmark of blended learning, which has been gaining popularity in elementary schools (Christensen et al. 2013). In a recent review, Pytash and O’Byrne (2018) describe blended learning as combining face-to-face instruction with online learning. Students have flexibility in accessing digital tools at various locations and times, and teachers can utilize online activities to adapt their instruction to meet individual students' needs, including those at-risk for academic failure. In fact, teachers can make use of real-time performance data offered in the digital component to provide individualized instruction. As pointed out by Shanahan and Lonigan (2010), individualized instruction that targets skill gaps can offer promising results for at-risk students experiencing early literacy struggles.

As highlighted by Repetto, Spitler, and Cox (2018), the opportunity to use digital tools offers at-risk students a chance to have some control over their learning, and can provide an environment that is more engaging and thus instill more motivation in students. However, 
given that it is a relatively new pedagogical approach, there is not a great deal of research on blended learning in elementary schools and with at-risk students (Pytash and O'Byrne 2018; Repetto et al. 2018).

There have been studies of instructional programs that include elements of blended learning in middle and high schools. For example, Lenhard et al. (2013) compared two programs to improve reading comprehension in sixth graders. One approach was teacherdirected and taught multiple strategies to build summarization skills, whereas the second approach used a digital program conText to provide constructive feedback on written summaries. The latter approach, which contained features of blended learning in that program use was embedded in the English Language Arts (ELA) curriculum as part of regular classroom instruction, was found to have a stronger impact on reading comprehension scores than the teacher-directed approach. In a large-scale randomized control study, Swanlund et al. (2012) examined the use of Read 180 (https://www.hmhco.com/programs/ read-180-universal) in five schools with students in grades six through nine. As part of Read 180, students were first administered an assessment tool designed to place them at the appropriate reading level in the program. Students were then instructed with a blended learning type model which began with daily whole group lessons. This was followed by rotations among small group instruction, use of the digital program and independent reading. The program featured three days of professional development in which teachers learned about program components, classroom management, providing small group lessons and how to use digital reports to differentiate instruction for students. Swanlund et al. reported that professional development support and teacher practices in the classroom were rated medium/high, but the actual amount of student usage of the digital technology fell in the low/medium range. Overall, reading outcome measures revealed a small but significant difference favoring treatment over control classes.

A few studies have addressed features of blended learning in elementary schools (Chambers et al. 2008; Torgesen et al. 2010). For instance, Chambers et al. (2008) used Success for All (https://www.successforall.org/) with first grade students from low SES families. Success for All is a school-wide instructional program that includes ongoing professional development, parental involvement and cooperative learning exercises among students. The program is highly intensive, combining whole-class instruction, multi-media activities and use of digital technology. Data tools provide feedback on how individual students are learning and where they need additional instruction. Individual tutoring sessions are incorporated into the program. The authors reported that participation in Success for All led to significant benefits on various measures of reading-word identification, passage fluency and reading comprehension.

\section{Core5}

Some recent studies have been conducted with a program called Lexia ${ }^{\circledR}$ Core $5^{\circledR}$ Reading. Core 5 is a fully-blended learning program which synchronizes the use of digital technology and offline materials employed by teachers in delivering their lessons. In an initial, small-scale experiment conducted by Schechter et al. (2015), it was found that first and second grade students from a low SES school who used Core5 showed greater gains than control students on a standardized test of reading skills. O'Callaghan et al. (2016) conducted a randomized controlled trial with 4- to 6-year old children and reported that those who used Core 5 showed greater improvements on tests of phonological skills than control children. Prescott et al. (2017) examined the effects of Core5 across elementary grades in 
a low SES school and found that improvements varied as a function of grade, with greater gains for students in earlier grades compared to later grades.

Building upon these studies, the present study aimed to investigate the effects of Core5 across grades using large samples of elementary school students. The opportunity to carry out this investigation occurred within a charter school network during the 2016-2017 school year. Some schools in the network elected to use Core5 and served as treatment schools while others decided to maintain their standard form of instruction and became control schools. Although we were unable to randomly assign schools to treatment and control conditions, the use of charter schools within the same network offered us a chance to compare schools with many similarities. Each school was governed by the same network-level administrators who regulate enrollment, oversee professional development, and offer a limited number of recommendations for curriculum, educational technology and assessments. All schools in the present study employed the same English Language Arts (ELA) curriculum and assessment tool. Finally, the ethnic profile across treatment and control schools was quite similar. Details about the curriculum, assessment tool and ethnic profiles are provided in the Methods section. Thus, in the context of a charter school network we had an opportunity to assess possible benefits of the blended learning program across multiple grades using comparable treatment and control schools.

Research studies have found the academic performance of students attending charter schools is similar to students attending public schools. As highlighted in a report sponsored by the U.S. Department of Education (Gleason et al. 2010), charter school students show large discrepancies in reading and math scores nationwide. In an extensive review of studies comparing charter schools to public schools, Blazer (2010) concluded that most studies that used strong methodological designs did not find advantages for charter schools over public schools. Just as many studies reported higher scores for public schools as studies that reported higher scores for charter schools. Thus, it is safe to say that the difficulties in achieving reading proficiency that apply to public schools apply to charter schools as well. Notably, one of the treatment schools in the present study had a high percentage of students from low SES backgrounds. As indicated earlier, these students may be considered at greater risk for not achieving reading proficiency.

\section{Research questions}

1. Does use of Core5 as part of blended learning support reading development in elementary school students compared to students receiving traditional instruction?

2. If there are benefits of blended learning over traditional instruction, do the benefits differ as a function of grade?

3. If there are benefits of blended learning over traditional instruction, do the benefits differ as a function of ethnic category?

\section{Method}

\section{Design}

This study utilized a quasi-experimental research design. Six charter schools located in the southeast United States were included in this study. Three of the schools were in the treatment group. Administrators in these schools had some concerns about the less proficient 
Table 1 Percentages in each grade for the treatment and control groups

\begin{tabular}{llllll}
\hline & \multicolumn{2}{l}{ Treatment group } & & \multicolumn{2}{l}{ Control group } \\
\cline { 2 - 3 } \cline { 5 - 6 } \cline { 5 - 6 } & Number & Percentage & & Number & Percentage \\
\hline Kindergarten & 415 & 18.7 & & 275 & 18.3 \\
First grade & 408 & 18.4 & & 275 & 18.3 \\
Second grade & 363 & 16.4 & & 264 & 17.6 \\
Third grade & 373 & 16.8 & & 233 & 15.5 \\
Fourth grade & 332 & 15.0 & & 240 & 16.0 \\
Fifth grade & 326 & 14.7 & & 217 & 14.4 \\
\hline
\end{tabular}

Table 2 Percentages in each ethnic category and receiving free/reduced price lunch for the treatment and control groups

\begin{tabular}{|c|c|c|c|c|c|c|}
\hline & \multicolumn{3}{|c|}{ Treatment group } & \multicolumn{3}{|l|}{ Control group } \\
\hline & School $1(\%)$ & School $2(\%)$ & School $3(\%)$ & School $4(\%)$ & School $5(\%)$ & School $6(\%)$ \\
\hline \multicolumn{7}{|l|}{ Ethnic category } \\
\hline $\begin{array}{l}\text { Hispanic } \\
\qquad(n=2149)\end{array}$ & 69 & 46 & 72 & 37 & 69 & 49 \\
\hline White $(n=717)$ & 13 & 32 & 13 & 22 & 13 & 28 \\
\hline Black $(n=494)$ & 7 & 11 & 7 & 28 & 7 & 14 \\
\hline Other $(n=361)$ & 11 & 11 & 8 & 13 & 11 & 9 \\
\hline $\begin{array}{l}\text { Free/reduced } \\
\text { lunch }\end{array}$ & 1 & 63 & 80 & 1 & 32 & 70 \\
\hline
\end{tabular}

Other included Unspecified (70.1\%), Asian (27.4\%) and American Indian (2.5\%). Percentages for free/ reduced price lunch are based on publicly available demographic information for the participating schools

readers in their schools and decided to make a change to their ELA curriculum and adopt Core5. Each of the treatment schools implemented Core5 for the first time during the 2016-2017 school year. Three other charter schools maintained their traditional form of instruction and served as the control group. These latter schools were selected for the study because, in aggregate, they showed a similar ethnic profile to the treatment schools (see Table 2).

\section{Participants}

Overall, there were 2217 students in the treatment group and 1504 students in the control group. These students were in kindergarten through fifth grade. All students who completed the Northwest Evaluation Association (NWEA) Measure of Academic Progress (MAP) Reading test (Measure of Academic Progress Reading Test 2016) in both Fall 2016 and Spring 2017 were included in the study. As seen in Table 1, there were highly similar percentages of students across grades in the treatment and control groups. Table 2 breaks down the treatment and control schools in terms of ethnic category and provides information regarding SES status for each school. The treatment and control schools showed similar distributions across ethnic categories, with the largest percentage of students being Hispanic. There was wide variation across schools in terms of percentage of students receiving 
free/reduced price lunch. The highest percent $(80 \%)$ was found in one of the treatment schools.

\section{English Language Arts}

Each school in this study used Wonders (https://www.mheducation.com/prek-12/program/ wonders-2020/MKTSP-BGA07M0.html) as part of their ELA curriculum. Wonders offers teacher-led instruction in foundational reading skills (e.g., phonological awareness, phonics, word analysis) as well as text comprehension and daily writing activities. It includes, as options, activities in Spanish and the use of digital technology for assessment purposes and to support reading instruction. For students in third through fifth grade, Reading Plus (https ://www.readingplus.com/) was added to the curriculum. Reading Plus is a digital program mainly designed to help inefficient readers improve their silent reading fluency. It includes an assessment tool used to assign texts to students at their reading level as well as elements of adaptive instruction - e.g., modified text to reduce processing demands - aimed to offer a personalized learning experience. The program also provides strategies to support vocabulary growth and text comprehension and said to boost motivation by allowing students a choice of which texts to read. Table 3 provides a comparison of the instructional programs used in the treatment and control schools.

\section{Core5}

For students in treatment schools, Core5 was incorporated into the ELA curriculum. Core5 provides a fully-blended learning model which combines systematic, structured activities within the digital component and offline materials for teachers to use in planning their lessons. The offline materials include Lexia Lessons ${ }^{\circledR}$ administered to students when they struggle with specific skills in the digital component, and paper-and-pencil tasks called Lexia Skill Builders ${ }^{\circledR}$ for students to work on independently to build automaticity and generalize skills beyond the digital component. Together, components of Core 5 offer students an individualized learning path to acquire reading skills. Contents in the digital component target six strands of reading: phonological awareness, phonics, structural analysis, automaticity/fluency, vocabulary, and comprehension. Activities in the strands address the Common Core State Standards (National Governors Association Center for Best Practices-Council of Chief State School Officers 2010) and are organized into 18 levels: preschool (Level 1), kindergarten (Levels 2-5), first grade (Levels 6-9), second grade (Levels 10-12), third grade (Levels 13-14), fourth grade (Levels 15-16), and fifth grade (Levels

Table 3 Comparison of instructional programs for the treatment and control schools

\begin{tabular}{lll}
\hline & Treatment schools & Control schools \\
\hline Kindergarten & Core5, Wonders & Wonders \\
First grade & Core5, Wonders & Wonders \\
Second grade & Core5, Wonders & Wonders \\
Third grade & Core5, Wonders, Reading Plus & Wonders, Reading Plus \\
Fourth grade & Core5, Wonders, Reading Plus & Wonders, Reading Plus \\
Fifth grade & Core5, Wonders, Reading Plus & Wonders, Reading Plus \\
\hline
\end{tabular}


17-18). Students begin the digital component with an embedded assessment that automatically places them in a level consistent with their reading ability. Students are required to complete each unit of an activity with $90 \%-100 \%$ accuracy before moving to subsequent units. For students who struggle in a unit, the program utilizes an adaptive branching rule to move them to a scaffolded task with fewer stimuli and more structure. If students continue to struggle, the program provides direct instruction that explicitly addresses the errors they made. Once students have successfully completed all activities at the standard, nonscaffolded step in a level, they are automatically advanced to the next level.

\section{Implementation training and support}

To support their implementation of Core5, teachers in the treatment schools were given an opportunity to participate in Lexia's Implementation Support Service Package (ISP). The ISP contains three training modules. The first is a "launch" module which instructs teachers on how to efficiently get started with Core 5 and reviews key components of Core5 including its scope-and-sequence and instructional materials. The second module called "data coaching" addresses progress monitoring in Core5, identifying students at-risk for reading difficulties, and planning instruction to target skill gaps. The data coaching module is offered around two months after the start of Core5. The third module called "instructional materials" focuses on implementing Core5 as part of a blended learning model and looks in more depth at the instructional materials (e.g., Lexia Lessons) available for teachers when planning offline lessons. The instructional materials module is offered any time following the data coaching module. Administrators at each treatment school decided which training modules to receive. Two treatment schools received the launch and data coaching modules, and the third treatment school received the data coaching and instructional materials modules.

\section{Digital component}

As part of implementation training, teachers were highly encouraged to have students use the digital component of Core 5 in accordance with recommended minutes (20 to $80 \mathrm{~min}$ per week). Recommended minutes are assigned monthly to students according to their risk level, which is based on their progress in Core 5 and estimates their likelihood of completing all Core 5 levels for their grade by the end of the school year. Teachers have access to an online implementation dashboard which allows them to track student usage. The dashboard also provides information about students who are struggling with digital activities, suggesting Lexia Lessons for teachers to deliver, and offers access to Lexia Skill Builders for students can work on once they have completed a level.

According to information provided to us by school liaisons, students were allowed to use the digital component of Core 5 at various times in an effort to reach their recommended minutes-during the ELA block, morning homeroom, before and after school, and even at home on weekends. To support use of the digital component at school, students had access to numerous electronic devices (iPads, mini-laptops, desktop computers) located in classrooms, shared among classrooms via a "laptop cart," and in computer laboratories. Students in the control group also had access to electronic devices to work on various math programs, Wonders, and Reading Plus in upper grades. 


\section{Offline materials}

Given that Core5 was designed as a blended learning program, it was expected that teachers would build a close alignment between students' performance in the online component and their offline work. Teachers were highly encouraged to track students' daily progress in the online component via the implementation dashboard and use these data to drive instructional plans (e.g., administering Lexia Lessons) in the classroom.

The school liaisons described how the offline materials were incorporated into the curriculum. When Lexia Lessons were used, they were typically administered by the teacher to a small-group of students as a center activity in the ELA block or, in some cases, by an interventionist in a pull-out session. Lexia Skill Builders were most commonly worked on independently by students in the ELA block.

\section{Assessment}

Students were pretested in the Fall 2016 and post-tested in the Spring 2017 with the NWEA MAP Reading Test (grade 3 through grade 5) or the NWEA MAP for Primary Grades Reading Test (kindergarten through grade 2). The MAP Reading Test assesses the following: Word Meaning and Vocabulary Knowledge, Understand and Integrate Key Ideas and Details for Literature and Informational Text, and Understand and Interpret Craft and Structure for Literature and Informational Text. The MAP for Primary Grades Reading Test assesses Foundational Skills, Vocabulary Use and Functions, Literature and Informational Text, and Language and Writing. The MAP is a computeradaptive test which captures reading achievement using RIT (Rasch unIT) scores. These scores fall on a continuous, equal-interval scale across grades.

\section{Analyses}

The analysis conducted for the Results was an analysis of covariance (ANCOVA) with main effects of treatment group, pretest, grade and ethnic category, and two-way interactions between treatment group and grade and between treatment group and ethnic category. The dependent variable was posttest RIT scores. To examine posttest differences between groups, post-hoc mean comparisons were run with Bonferroni corrections for multiple tests.

\section{Results}

In the first section below we provide descriptive statistics regarding student use of the digital component of Core5. The second section establishes the use of pretest RIT scores as a covariate in the ANCOVA. The last section presents outcomes from conducting the ANCOVA. 


\section{Program use}

Overall, students in the treatment group showed relatively strong use of the digital component of Core5. The program records the date, login time, and logout time for each session of use. From these data, we determine the number of weeks of use and overall minutes of use per week. The mean number of weeks of use and the mean number of minutes of use over the school year were 26.0 and 2038.6, respectively. Students used the digital component for an average of 78.4 min per week. A look at mean number of minutes over the school year showed discrepancies across grades: use was strongest in second grade (2651.4) and third grade (2396.2), lower in kindergarten (2099.3) and first grade (2146.6), and weakest in fourth grade (1569.8) and fifth grade (1209.9).

\section{Pretest means}

To establish the use of pretest RIT scores as a covariate, an independent sample $t$-test was run comparing pretest means for the two groups. The $t$-test showed a significant difference $(t(3720)=3.821, p<.001)$ favoring the control group (177.68) over the treatment group (174.24). The significant pretest difference affirms the concerns expressed by administrators at the treatment schools. Their students displayed limitations in reading proficiency which led them to change the ELA curriculum and implement the blended learning program.

\section{ANCOVA}

The ANCOVA model included main effects of treatment group, pretest, grade and ethnic category, and two-way interactions between treatment group and grade and between treatment group and ethnic category. There was a significant effect of treatment group $(F(1,3703)=14.822, p<.001)$. The marginal posttest mean for the treatment group (189.61, $S E=0.27)$ was significantly higher than the marginal mean for the control group (188.07, $S E=0.30)$. There was also a significant effect of grade $(F(5,3703)=9.199, p<.001)$. Post-hoc comparisons revealed that students in third grade obtained a higher marginal posttest mean $(191.07, S E=0.44)$ than students in kindergarten $(187.31, S E=0.56)$, first grade $(188.37$, $S E=0.42)$, second grade $(189.14, S E=0.41)$ and fourth grade $(187.87, S E=0.51)$. Lastly, there was a significant effect of ethnic category $(F(3,3703)=12.341, p<.001)$. Students categorized as Other $(190.25, S E=0.51)$ or White $(189.67, S E=0.37)$ had higher marginal posttest means than students categorized as Black $(187.73, S E=0.44)$ or Hispanic (187.72, $S E=0.22$ ).

\section{Treatment group $\times$ grade}

The interaction between treatment group and grade was not significant $(F(5,3703)=1.247$, $p=.284$ ). This indicates that the treatment effect was consistent across grades. Table 4 shows the treatment and control group marginal posttest means for each grade.

\section{Treatment group $\times$ ethnic category}

The interaction between treatment group and ethnic category was also not significant $(F(3,3703)=1.973, p=.116)$. Thus, the treatment effect applied equally across students in 
Table 4 Marginal post-test mean RIT scores and standard errors for each grade

\begin{tabular}{llllll}
\hline & \multicolumn{2}{l}{ Treatment group } & & \multicolumn{2}{l}{ Control group } \\
\cline { 2 - 3 } & Mean & $S E$ & & Mean & $S E$ \\
\hline Kindergarten & 187.87 & 0.64 & & 186.75 & 0.72 \\
First grade & 188.63 & 0.54 & & 188.11 & 0.62 \\
Second grade & 190.62 & 0.54 & & 187.66 & 0.62 \\
Third grade & 192.09 & 0.54 & & 190.05 & 0.66 \\
Fourth grade & 188.38 & 0.61 & & 187.36 & 0.71 \\
Fifth grade & 190.07 & 0.65 & & 188.51 & 0.76 \\
\hline
\end{tabular}

\begin{tabular}{llllll}
\hline & \multicolumn{2}{l}{ Treatment group } & & \multicolumn{2}{l}{ Control group } \\
\cline { 2 - 3 } \cline { 6 - 6 } & Mean & $S E$ & & Mean & $S E$ \\
\hline Hispanic & 188.55 & 0.27 & & 186.89 & 0.34 \\
White & 191.22 & 0.48 & & 188.11 & 0.56 \\
Black & 188.20 & 0.58 & & 187.26 & 0.66 \\
Other & 190.48 & 0.70 & & 190.02 & 0.75 \\
\hline
\end{tabular}

Table 5 Marginal post-test mean RIT scores and standard errors for each ethnic category

different ethnic categories. Table 5 shows the treatment and control group marginal posttest means for each ethnic category.

\section{Discussion}

This quasi-experimental study examined the potential benefits of a blended learning approach to reading instruction in elementary schools. We investigated the use of blended learning with large samples of students in treatment and control groups from the same charter school network. After controlling for pretest differences between groups, we found that the treatment group produced significantly higher posttest reading scores than the control group. This outcome offers an affirmative response to the first research question. The use of digital technology as part of blended learning supports reading development in elementary school students compared to traditional instruction.

Using treatment and control schools from the same charter school network allowed us to compare groups of students receiving instruction in similar educational environmentsincluding administrative oversight and policies, ELA curriculum and testing protocols. Administrators in the treatment schools elected to adopt the blended learning program to support the less proficient readers in their schools. Students in these schools were compared to students in control schools selected because their students showed similar ethnic profiles to students in the treatment schools. Concerns about less proficient readers in the treatment group were validated by scores on the NWEA MAP assessment - the pretest mean for the treatment group was significantly lower than for the control group.

The findings in this study extend previous work showing that, in general, aspects of blended learning can support reading skill development (Chambers et al. 2008; Lenhard et al. 2013; Swanlund et al. 2012) and, in particular, the fully-blended program used hereCore 5-is beneficial for elementary school students. The greater gains found in schools 
using Core 5 compared to control schools are consistent with earlier studies by Schechter et al. (2015) and O'Callaghan et al. (2016).

In response to the second research question, we did not find a significant interaction between treatment group and grade. The overall benefits of blended learning (treatment group) compared to traditional instruction (control group) did not differ as a function of grade. There was, however, a significant effect of grade. Collapsed over treatment and control groups, reading scores for students in third grade were generally higher than the other grades. Without more information about differences in grade-level instruction within the charter school network, it is uncertain why these differences occurred.

As in the case of grade, the interaction between treatment group and ethnic category was not significant. Thus, in response to the third research question, the overall benefits of blended learning (treatment group) over traditional instruction (control group) did not differ as a function of ethnic category. However, there was a significant effect of ethnic category. Collapsed over treatment and control groups, it was found that students categorized as Other or White had higher reading scores than students categorized as Black or Hispanic. The outcome comparing White students with Black and Hispanic students is consistent with national trends in reading proficiency levels across ethnic categories (National Center for Education Statistics 2017). For students categorized as Other, most had their ethnicity left "unspecified" (70\%). Without knowing their ethnic profiles, it is difficult to speculate on why Other students showed higher reading scores in this study.

One of the main features of blended learning, which distinguishes it from traditional forms of instruction, is that it is designed to couple the use of digital technology with teacher-led instruction. The use of blended learning is considered to be more engaging for students than traditional forms of instruction (Repetto et al. 2018). With Core5 as the blended learning program, a close alignment is established between students' performance in the online component and recommended offline work. Teachers were highly encouraged to track students' daily progress in the online component via the implementation dashboard and use these data to drive instructional plans (e.g., administering Lexia Lessons) in the classroom. When implemented successfully, this can be an effective way to target the specific needs of individual students. In contrast to the blended learning approach utilized in this study, most schools that employ a traditional form of instruction use digital technology in a less integrated way (Vega and Robb 2019). Though we did not carefully assess how the control schools in this study used the digital elements of Wonders and Reading Plus as part of their ELA curriculum, it does not appear that they were integrated into a blended learning model. Blended learning was considered a novel way to deliver reading instruction among administrators in the charter school network.

A main concern in U.S. schools today is how often students show limited reading proficiency at the end of elementary school-especially students from low SES backgrounds. One of the treatment schools in this study served a large percentage of students (80\%) who received free/reduced price lunch. Students in this school gained 13.70 points in terms of mean RIT scores, which is nearly identical to the mean RIT score gain (13.61) for the whole treatment group. Thus, the blended learning program showed promising effects for students from low SES backgrounds.

\section{Limitations}

This study utilized a quasi-experimental design in which certain administrators in a charter school network decided to use the blended learning program in their schools. These 
treatment schools were compared to control schools selected from the same charter school network based on having similar ethnic profiles as the treatment schools. With this design there are a number of possible confounding variables, such as teacher background in reading instruction, parental involvement, and after school activities, which may have differed across schools and contributed to the outcomes. Second, we did not probe how teachers in the treatment classes decided to implement the blended learning program in their classrooms to identify which elements of the program - training sessions, student engagement in the online program, the implementation dashboard, teacher-led lessons, use of offline materials - may have contributed to reading gains in the treatment group. Third, we failed to capture enough information about reading instruction in the control schools to identify how use of technology in control classes differed from the blended learning approach used in treatment classes. Thus, this study should be framed as the beginning of research efforts to systematically explore how various features of blended learning (e.g., implementation approaches used by teachers, student engagement, use of offline materials) can impact learning in elementary schools.

\section{Conclusions}

To conclude, this study extends the findings of previous work demonstrating benefits of blended learning for elementary school students. Significant outcomes were obtained using large samples of students across multiple treatment and control schools. In addition, benefits were found not only for students in younger grades (see Schechter et al. 2015) but for students in upper grades, and for students with different ethnic backgrounds. For a blended learning program such as Core 5 to be effective, a solid commitment from administrators at all levels in an organization (school district or charter school network) is essential so that all aspects of the program (e.g., use of digital technology, classroom resources, scheduling) are fully supported (Moskal et al. 2013). In addition, because implementation of a new instructional program takes time and experience to perfect, it is wise to invest in the program over multiple years, in which case the benefits may be quite striking (Macaruso et al. 2019). When administrators of control schools in the present study were made aware of our findings, they decided to implement Core 5 in their schools during the next school year.

\section{Compliance with ethical standards}

Conflict of interest This submission evaluates the effectiveness of a commercial product. The second and third author were employed by Lexia ${ }^{\circledR}$ Learning, a Rosetta Stone ${ }^{\circledR}$ Company at the time of data collection, and the first author serves as a paid consultant and is employed by Community College of Rhode Island. None of the researchers receive commission on sales of the products. Teachers and school personnel carried out the implementation of the blended learning program independently.

Open Access This article is licensed under a Creative Commons Attribution 4.0 International License, which permits use, sharing, adaptation, distribution and reproduction in any medium or format, as long as you give appropriate credit to the original author(s) and the source, provide a link to the Creative Commons licence, and indicate if changes were made. The images or other third party material in this article are included in the article's Creative Commons licence, unless indicated otherwise in a credit line to the material. If material is not included in the article's Creative Commons licence and your intended use is not permitted by statutory regulation or exceeds the permitted use, you will need to obtain permission directly from the copyright holder. To view a copy of this licence, visit http://creativecommons.org/licenses/by/4.0/. 


\section{References}

Blazer, C. (2010). Literature review: Research comparing charter schools and traditional public schools. Miami, FL: Miami-Dade County Public Schools.

Chambers, B., Slavin, R. E., Madden, N. A., Abrami, P. C., Tucker, B. J., Cheung, A., et al. (2008). Technology infusion in success for all: Reading outcomes for first graders. The Elementary School Journal, 109, 1-15. https://doi.org/10.1086/592364.

Chauhan, S. (2017). A meta-analysis of the impact of technology on learning effectiveness of elementary students. Computers \& Education, 105, 14-30. https://doi.org/10.1016/j.compedu.2016.11.005.

Cheung, A. C. K., \& Slavin, R. E. (2013). Effects of educational technology applications on reading outcomes for struggling readers: A best-evidence synthesis. Reading Research Quarterly, 48, 277-299. https://doi.org/10.1002/rrq.50.

Christensen, C. M., Horn, M. B., \& Staker, H. (2013). Is K-12 blended learning disruptive? An introduction to the theory of hybrids. Retrieved from https://www.christenseninstitute.org/wp-content/uploa ds/2014/06/Is-K-12-blended-learning-disruptive.pdf.

Cuban, L. (1986). Teachers and machines: The classroom use of technology since 1920. New York, NY: Teachers College Press.

Fiester, L. (2013). Early warning confirmed: A research update on third-grade reading. Retrieved from Baltimore, MD. https://www.aecf.org/resources/early-warning-confirmed/.

Gleason, P., Clark, M., Tuttle, C. C., \& Dwoyer, E. (2010). The evaluation of charter school Impacts: Final report (NCEE 2010-4029). Retrieved from Washington, DC. https://ies.ed.gov/ncee/pubs/20104029/ pdf/20104030.pdf.

Herold, B. (2019, April 24). Ed-tech supporters promise innovations that can transform schools. Teachers not seeing impact. Retrieved from https://www.edweek.org/.

Lenhard, W., Baier, H., Endlich, D., Schneider, W., \& Hoffmann, J. (2013). Rethinking strategy instruction: Direct reading strategy instruction versus computer-based guided practice. Journal of Research in Reading, 36, 223-240. https://doi.org/10.1111/j.1467-9817.2011.01505.x.

MacArthur, C. A., Ferretti, R. P., Okolo, C. M., \& Cavalier, A. R. (2001). Technology applications for students with literacy problems: A critical review. Elementary School Journal, 101, 273-301. https://doi. org/10.1086/499669.

Macaruso, P., Wilkes, S., Franzén, S., \& Schechter, R. (2019). Three-year longitudinal study: Impact of a blended learning program-Lexia ${ }^{\circledR}$ Core $5 \AA$ Reading —on reading gains in low-SES kindergarteners. Computers in the Schools, 36, 2-18. https://doi.org/10.1080/07380569.2018.1558884.

Measure of Academic Progress Reading Test. (2016). Portland, OR: Northwest Evaluation Association.

Moskal, P., Dziuban, C., \& Hartman, J. (2013). Blended learning: A dangerous idea? The Internet and Higher Education, 18, 15-23. https://doi.org/10.1016/j.iheduc.2012.12.001.

National Center for Education Statistics. (2017). Local education agency universe survey data. Retrieved from https://nces.ed.gov/ccd/pubagency.asp.

National Governors Association Center for Best Practices-Council of Chief State School Officers. (2010). Common Core State Standards. Retrieved from Washington, DC. https://www.corestandards.org/ELALiteracy/.

O’Callaghan, P., McIvor, A., McVeigh, C., \& Rushe, T. (2016). A randomized controlled trial of an earlyintervention, computer-based literacy program to boost phonological skills in 4- to 6-year-old children. British Journal of Educational Psychology, 86, 546-558. https://doi.org/10.1111/bjep.12122.

Prescott, J. E., Bundschuh, K., Kazakoff, E., \& Macaruso, P. (2017). Elementary school-wide implementation of a blended learning program for reading intervention in a Title I school: Implications for students who are English Learners. Journal of Educational Research, 1-10.

Putman, R. S. (2017). Technology versus teachers in the early literacy classroom: An investigation of the effectiveness of the Istation integrated learning system. Educational Technology Research and Development, 65, 1153-1174. https://doi.org/10.1007/s11423-016-9499-5.

Pytash, K. E., \& O’Byrne, W. I. (2018). Research on literacy instruction and learning in virtual, blended, and hybrid environments. In K. Kennedy \& R. E. Ferdig (Eds.), Handbook of research on K-12 online and blending learning (2nd ed., pp. 303-314). Pittsburgh, PA: Carnegie Mellon University Press/ETC Press.

Repetto, J. B., Spitler, C. J., \& Cox, P. R. (2018). Research on at-risk learners in K-12 online learning. In K. Kennedy \& R. E. Ferdig (Eds.), Handbook of research on $\mathrm{K}-12$ online and blending learning (2nd ed., pp. 107-134). Pittsburgh, PA: Carnegie Mellon University Press.

Schechter, R., Macaruso, P., Kazakoff, E. R., \& Brooke, E. (2015). Exploration of a blended learning approach to reading instruction for low SES students in early elementary grades. Computers in the Schools, 32, 183-200. 
Shanahan, T., \& Lonigan, C. J. (2010). The national early literacy panel. Educational Researcher, 39, 279285. https://doi.org/10.3102/0013189x10369172.

Swanlund, A., Dahlke, K., Tucker, N., Kleidon, B., Kregor, J., Davidson-Gibbs, D., et al. (2012). Striving readers: Impact study and project evaluation report: Wisconsin Department of Public Instruction (with Milwaukee Public Schools). Naperville, IL: American Institutes for Research.

Torgerson, C., \& Zhu, D. (2004). Evidence for the effectiveness of ICT on literacy learning. In R. Andrews (Ed.), The impact of ICT on literacy education (pp. 34-68). New York, NY: Routledge Falmer.

Torgesen, J. K., Wagner, R. K., Rashotte, C. A., Herron, J., \& Lindamood, P. (2010). Computer-assisted instruction to prevent early reading difficulties in students at risk for dyslexia: Outcomes from two instructional approaches. Annals of Dyslexia, 60, 40-56. https://doi.org/10.1007/s11881-009-0032-y.

Vega, V., \& Robb, M. B. (2019). The Common Sense census: Inside the 21 st-century classroom. San Francisco, CA: Common Sense Media.

Publisher's Note Springer Nature remains neutral with regard to jurisdictional claims in published maps and institutional affiliations.

Paul Macaruso is a Professor in the Psychology Department at the Community College of Rhode Island. His research centers around developmental disorders in reading and mathematics and the use of computerassisted technology to support reading acquisition in children.

Shani Wilkes was a Senior Research Manager at Lexia at the time of this project, and is currently the Senior Director of Research and Evaluation at the Combined Jewish Philanthropies. She has experience conducting research and evaluation projects across a host of topic areas, including K-12, afterschool programs, criminal justice interventions and other community-based prevention and intervention programs.

Jen Elise Prescott was a Lead Analyst at Lexia at the time of this project, and is currently serving as the Deputy Director of Research and Analysis in the Office of Performance Management of the Massachusetts Bay Transportation Authority. She has methodological expertise in data visualization and database management, and substantive experience in child development and community-based programs. 